*Doutorado em Direito em 2004 pela Pontifícia Universidade Católica de Minas Gerais, (PUCMG)

Mestrado em Direito em 2000 pela Pontifícia Universidade Católica de Minas Gerais, (PUC-MG)

Especialista em Direito em 1999

pela Pontifícia Universidade Católica de Minas Gerais, (PUCMG)

Graduado em Direito em 1998 pela Pontifícia Universidade Católica de Minas Gerais, (PUCMG)

E-mail: amagalhaes@ig.com.br

**Doutorado em Direito em andamento pela Pontifícia Universidade Católica de Minas Gerais, (PUC-MG)

Mestra em Direito Privado em 2018 pela Pontifícia Universidade Católica de Minas Gerais, (PUCMG)

Especialista em Direito Empresarial em 2014 pela Fundação Getúlio Vargas (FGV)

Graduada em Direito em 2011

Pontifícia Universidade Católica de Minas Gerais, (PUC-MG)

E-mail: amagalhaes@ig.com.br

\section{Arbitragem Eletrônica}

\author{
Electronic Arbitrage
}

Rodrigo Almeida Magalhães*
Marina de Souza Saraiva**

Como citar: MAGALHÃES, Rodrigo Almeida; SARAIVA, Marina de Souza . Arbitragem Eletrônica. Scientia Iuris, Londrina, v. 23, n. 2, p. 26-41, jul. 2019. DOI: 10.5433/2178-8189.2019v23n2p26. ISSN: 2178-8189.

Resumo: $O$ presente trabalho tem como objetivo realizar um estudo sobre o uso da arbitragem na era digital, tema que envolve, como se verá, pontos sensíveis e de complexa análise. Para compreensão do assunto, realizar-se-á a observação da nova situação paradigmática estabelecida pela denominada quarta Revolução Industrial. Buscar-se-á, também, observar os novos conflitos e as formas de solucioná-los dentro desse novo cenário, fazendo-se, nesse contexto, o estudo do desenvolvimento do Online Dispute Resolution (ODR). No que tange à arbitragem, na era digital, ponto central desse trabalho, examinar-se-á a forma, as peculiaridades e a conveniência do uso de recursos tecnológicos no desenvolvimento desse método, bem como as implicações legais referentes ao tema.

Palavras-chave: Quarta revolução industrial. Métodos eletrônicos de solução de controvérsias. Arbitragem.

Abstract: The present work has the objective of conducting a study on the use of arbitration in digital age, a topic that involves, as will be seen, sensitive points and a complex analysis. To understand the subject, we will observe the new paradigmatic situation established by the so-called forth Industrial Revolution. It also seeks to observe the new conflicts and ways of solving them within this new scenario, realizing the study of the development of Online Dispute Resolution (ODR). Regarding arbitration in the digital age, the central point of this work, will be examined the form, peculiarities, implications and the convenience of the use of technological resources in the development of this method, as well as the legal implications related to the subject.

Keywords: Forth industrial revolution. Online dispute resolution. Arbitration. 


\section{INTRODUÇÃO}

O desenvolvimento tecnológico ao longo da história da humanidade culminou diversas vezes em mudanças paradigmáticas na forma como a sociedade se desenvolve. $\mathrm{O}$ direito, nesse contexto, é afetado e modifica-se atendendo à nova realidade estabelecida.

A denominada quarta Revolução Industrial, trouxe mudanças impactantes que continuam em curso, atualizando e alterando constantemente a forma como os seres humanos estabelecem suas relações em sociedade.

O presente trabalho, compreendendo esse panorama, tem como objetivo observar, especialmente do ponto de vista jurídico, o impacto da mencionada revolução no surgimento de conflitos e na forma como esses são resolvidos.

Em especial, o estudo pretende analisar os métodos adequados de solução de controvérsias na era digital, com foco na observação do desenvolvimento da arbitragem.

Como se verá, o tema envolve múltiplas questões complexas. Nesse sentido, não se pretende esgotar a análise da problemática concernente ao tema, mas indicar um panorama global da situação estabelecida, fomentando a disseminação de informações e reflexões, com a finalidade de contribuir para o desenvolvimento de ideias que possam amenizar ou por termo nos obstáculos encontrados para o uso dos mencionados métodos, especialmente tratando-se da arbitragem, técnica reconhecidamente relevante para o desenvolvimento do comércio interno e internacional.

\section{A QUARTA REVOLUÇÃO INDUSTRIAL}

A expressão revolução pode ser compreendida como o ato de revolver. É caracterizada por uma mudança na estrutura organizacional de uma sociedade ou por uma modificação fundamental no poder político de uma sociedade, configurado em um curto intervalo de tempo. É um termo que também pode ser adotado para designar mudanças céleres nos campos econômico, científico, comportamental e tecnológico. (CONTREIRAS, 2015).

Schwab (2016) publicou, em razão dos assuntos abordados no Fórum Econômico Mundial, a obra intitulada a $4^{\mathrm{a}}$ Revolução Industrial ${ }^{1}$, realizando análise das implicações e características do momento tecnológico que a humanidade vivencia.

$\mathrm{O}$ autor menciona que a humanidade passou por diversas mudanças na forma de viver. A primeira delas ocorreu a cerca de 10.000 anos, com o surgimento da agricultura, que só foi possível a partir da domesticação dos animais. $\mathrm{O}$ homem, nesse contexto, passou a unir a sua força à dos animais para produção, não sendo mais necessária a busca por alimentos. Essa situação possibilitou que os seres humanos se assentassem, levando ao surgimento de aldeias e, posteriormente, de cidades. Tal cenário criou um ambiente favorável também para o desenvolvimento do transporte, da produção e da comunicação.

A revolução agrícola foi então seguida por diversas revoluções industriais que tiveram início no século XVIII, culminando na substituição da força muscular pela mecânica.

1 A referida obra foi utilizada como base para elaboração dessa seção. 
A primeira Revolução Industrial sucedeu entre os anos 1760 e 1840 e ocorreu principalmente em razão da construção de ferrovias e da criação das máquinas a vapor. A segunda teve início no fim do século XIX e teve como elementos principais a invenção da eletricidade e da linha de montagem, permitindo a produção em massa. A terceira Revolução iniciou-se na década de 60 e é comumente denominada revolução digital, considerando principalmente as mudanças trazidas pelo desenvolvimento e uso dos computadores, dos semicondutores e da internet.

A quarta Revolução Industrial, atualmente em curso, teve início na virada desse século e tem como base a revolução digital, possuindo como elementos de destaque a internet onipresente e móvel, os sensores poderosos e menores, que se tornam cada vez mais baratos, bem como a inteligência artificial. Destaca-se, contudo, que o aspecto mais relevante do atual momento diz respeito à integração e sofisticação de todas as tecnologias que se desenvolvem e se comunicam concomitantemente. De maneira geral, a diferença fundamental da quarta Revolução Industrial em relação às demais diz respeito a atual fusão e interação das tecnologias no que tange aos domínios digitais, biológicos e físicos ${ }^{2}$.

Sobre a complexidade do panorama atual, Schwab (2016, p. 11) ensina que:

Ainda precisamos compreender de forma mais abrangente a velocidade e a amplitude dessa nova revolução. Imagine as possibilidades ilimitadas de bilhões de pessoas conectadas por dispositivos móveis, dando origem a um poder de processamento, recursos de armazenamento e acesso ao conhecimento sem precedentes. Ou imagine a assombrosa profusão de novidades tecnológicas que abrangem numerosas áreas: inteligência artificial (AI), robótica, a internet das coisas (IoT, na sigla em inglês), veículos autônomos, impressão em 3D, nanotecnologia, biotecnologia, ciência dos materiais, armazenamento de energia e computação quântica, para citar apenas algumas. Muitas dessas inovações estão apenas no início, mas já estão chegando a um ponto de inflexão de seu desenvolvimento, pois elas constroem e amplificam umas às outras, fundindo as tecnologias dos mundos físico, digital e biológico.

Assim, a revolução que se vivencia, por sua complexidade, acarreta também em uma multiplicidade de desafios que devem ser encarados para que seja possível obter o melhor proveito dessa conjuntura. As possíveis rupturas engendradas por essa quarta fase, tão dinâmica, veloz e fascinante, devem ser bem analisadas e compreendidas para que seja dado o tratamento adequado à situação. Esta "Revolução Industrial, e a consequente revolução eletrônica, além de um sistema produtivo e socioeconômico, deve ser olhada, desde o presente, e pensada, como o começo de uma nova fase da civilização humana" (DI FELICE, 2007, p. 3)

É dentro desse contexto que o presente trabalho pretende abordar os impactos de tantas

2 É importante ressaltar que as revoluções mencionadas não são vivenciadas no Globo de forma homogênea. Sabe-se que boa parte da população mundial ainda não possui, sequer, acesso à internet e, em muitos casos, até à eletricidade. Conforme ensina Natalino "Em países em desenvolvimento, cerca de 1,6 bilhão de pessoas não tem acesso à eletricidade e 2,4 bilhões de indivíduos ainda utilizam combustíveis tradicionais (lenha e carvão, principalmente) para aquecimento e preparo de alimentos". (NATALINO, 2017, p. 175-176). Essa situação indica uma profunda desigualdade de acesso às tecnologias, configurando-se um obstáculo adicional para o enfrentamento dessa mudança paradigmática. 
mudanças no surgimento e na resolução de conflitos, considerando o entendimento de que é necessário ter, dentro de todo esse cenário estabelecido, "uma visão compartilhada abrangente e global sobre como a tecnologia tem mudado nossas vidas e mudará a das gerações futuras, e sobre como ela está remodelando o contexto econômico, social, cultural e humano em que vivemos" (SHWAB, 2016, p. 12), para que possamos contornar eventuais problemas e utilizar todo o potencial tecnológico atual e futuro em benefício da sociedade.

\section{ONLINE DISPUTE RESOLUTION - ODR}

Como mencionado, a tecnologia promovida no contexto da quarta Revolução Industrial alterou de forma impactante a forma como as pessoas interagem. Observa-se, assim, uma mudança paradigmática em curso no modo como as pessoas trabalham, se comunicam, bem como nas formas que se expressam, se informam e se divertem. (SCHWAB, 2016).

Sabe-se que o conflito é algo inerente à vida em sociedade, vez que "desacordos e problemas podem surgir em quase todos os relacionamentos" (MOORE, 1998, p. 22). Pode-se considerá-lo inevitável quando se trata de relações ou relacionamentos humanos, tanto entre pessoas físicas quanto entre pessoas jurídicas.

O termo pode ser compreendido como "uma divergência de perspectivas, percebida como geradora de tensão por, pelo menos, uma das partes envolvidas numa determinada interação, e que pode ou não se traduzir numa incompatibilidade de objetivos" (DIMAS; LOURENÇO; MIGUEZ, 2007, p. 38).

Dessa forma, não é difícil imaginar que todo ser humano inserido na sociedade, ao longo de sua existência, depara-se com situações conflituosas, considerando ser algo que faz parte da convivência em grupo, fruto de interesses, opiniões, pontos de vista e necessidades que divergem de um indivíduo para o outro. A forma como o conflito é tratado é que determinará o alcance e as consequências da divergência. (MORAIS, 2015, p. 71).

Considerando ser o conflito inerente às relações sociais, a alterações na forma de interação entre as pessoas influencia diretamente a formação de divergências. Amorim (2017) argumenta que o desenvolvimento tecnológico relativo à transmissão de dados e de informação alterou definitivamente a forma como os indivíduos se relacionam, repercutindo, ainda, nas relações jurídicas que passam a ser estabelecidas também no ciberespaço. O autor indica que "As relações jurídicas firmadas no ciberespaço instauram uma nova forma de relacionamento com o real, criando outras fontes de normatividade, exigindo do Direito uma revisão de seus paradigmas." (AMORIM, 2017, p. 516).

No mesmo sentido, Eckschmidt, Magalhães e Muhr (2016, p. 63-64), ensinam que:

Cada nova tecnologia tem o potencial de criar novos problemas e novas formas de solucionar os conflitos. A tecnologia tem transformado a forma como as pessoas se comunicam. Há 30 anos, $50 \%$ da população nunca havia feito uma ligação telefônica. [...] A invenção do carro criou disputas de seguro de acidentes, os telefones criaram novos conflitos relacionados a ligações indesejadas. As 
inovações mudam aspectos sociais das pessoas, assim como as maneiras como alguns conflitos são abordados.

Dessa maneira, quando se trata da quarta Revolução Industrial, pode-se concluir que o objeto dos conflitos e a forma de sua ocorrência sofreram mudanças, assim como os modos de solução demandas.

Os denominados Online Dispute Resolutions - ODR ou Métodos Eletrônicos de Solução de Controvérsias - MESC vêm sendo cada vez mais utilizados e discutidos, em razão da conveniência, adequação e, em determinados casos, por sua imprescindibilidade para a resolução de determinados tipos de litígios.

Os MESC têm origem a partir do desenvolvimento dos Alternative Dispute Resolutions - ADR ou, como também são chamados na língua portuguesa, Métodos Adequados de Solução de controvérsias - MASC.

Os ADR ou MASC floresceram nas últimas décadas, passando a ser cada vez mais utilizados, a partir da atual abordagem sobre o acesso à justiça, que será posteriormente detalhada nesse estudo. Dentro desse panorama, os MASC são observados atualmente como meios capazes de, assim como o Poder Judiciário, solucionar controvérsias de forma justa e adequada. São frequentemente citadas, como exemplo de métodos adequados, a negociação, a mediação, a conciliação e arbitragem.

Os MESC ou ODR são, portanto, uma variação dos ADR ou MASC, a partir do uso de tecnologia que propicia a resolução de disputas no ambiente eletrônico.

Sobre os ODR, Amorim ensina que:

Os modos de Resolução Online de Litígios (Online Dispute Resolution ODR) consistem, portanto, na utilização dos recursos da tecnologia para a Resolução Alternativa de Litígios - ADR, quer sejam estes decorrentes exclusivamente das relações jurídicas firmadas no ciberespaço, quer sejam originários de relações jurídicas constituídas no mundo dito "físico". Nesse sentido, ODR pode ser considerado espécie do gênero ADR. Mas seria demasiado simplista imaginar que os meios de Resolução Online Litígios sejam reduzidos a uma simples expressão dos meios de Resolução Alternativa de Controvérsias . As possibilidades de utilização da tecnologia para a resolução de litígios são imensas e envolvem questões complexas, tanto do ponto de vista teórico quanto sob o prisma tecnológico, como, por exemplo, a utilização de inteligência artificial para fornecer uma solução para o conflito. [...] Sob uma perspectiva mais pragmática, os sistemas informatizados e as plataformas de transmissão e recepção de dados constituem um terceiro interveniente no processo de conciliação, ou até mesmo podem constituir um quarto sujeito, nos casos da mediação e da arbitragem online. (AMORIM, 2017, p. 515).

Do ponto de vista histórico, Katsh e Rifikin (2001) ensinam que o uso dos ODR pode ser dividido em três fases. O primeiro estágio perdurou até aproximadamente o ano de 1995, quando 
os métodos se mantinham adstritos praticamente à resolução de controvérsias ligadas a usuários e provedores de e-mail, permanecendo a sua utilização em contextos específicos. A segunda fase ocorreu entre os anos de 1995 e 1998, quando foi percebida a necessidade do uso de meios eletrônicos para solução de controvérsias que surgiam no ciberespaço de forma geral. Na terceira fase, que teve início em 1998 estendendo-se até os dias atuais, passa-se a compreender os MESC como capazes de resolver conflitos surgidos tanto fora como dentro do ambiente eletrônico.

Amorim (2017) menciona quatro experiências percursoras dos ODR. São elas: o Virtual Magistrate Program, criado nos EUA em 1995 com o objetivo de fornecer soluções rápidas para controvérsias que envolvessem usuários e operadores de rede ou provedores de acesso à internet; o Online Ombus Office, criado em 1996 também nos EUA, com a finalidade de solucionar litígios referentes a nomes de domínios, usuários e provedores de acesso à internet, grupos de discussão e propriedade intelectual; o CyberTribunal, implantado no Canadá em 1996, com o objetivo de prevenir e resolver litígios online surgidos exclusivamente na internet, fazendo uso de procedimentos de mediação e de arbitragem para tanto; e, por fim, o Sistema de Resolução de Controvérsias sobre Nomes de Domínio na Internet (Uniform Dispute Resolution Policy URDP) da ICCAN (Internet Corporation for Assigned Names and Numbers), criado em 1999 com a finalidade de regular conflitos referentes à atribuição de nomes de domínio na internet, sendo a primeira experiência transnacional de resolução online de conflitos.

Atualmente, o uso dos MESC é realizado em maior escala, especialmente quando se trata de resolução de disputas de origem virtual. Como exemplo, os empresários do comércio eletrônico, como o eBay e o Mercado Livre, podem ser mencionadas. A partir da percepção da necessidade de lidar com as expectativas não satisfeitas de seus clientes, esses empresários passaram a desenvolver plataformas próprias para solução de controvérsias entre consumidores e vendedores.

O desenvolvimento dos ODR foi em grande parte impulsionado pela globalização e difusão do uso da internet, que aumentaram a interação e os negócios entre pessoas situadas fisicamente muito distantes uma das outras. Essencialmente, no caso dos consumidores e fornecedores, a resolução de disputas nessas circunstâncias de distanciamento tornou-se especialmente comprometida, vez que praticamente inviável o uso de métodos físicos de solução de disputas.

Neste sentido, Amorim (2017, p. 530) ensina que:

No momento em que a transmissão e difusão de dados numéricos ultrapassa as fronteiras físicas entre os países, encurtando distâncias e aproximando os indivíduos, resta evidente que os processos tradicionais de que fazem uso os meios de Resolução Alternativa de Conflitos tornam-se cada vez mais irrelevantes, quiçá obsoletos. Assim ocorre porque os ADR fundamse basicamente na resolução de conflitos face-a-face, ou F2F (face-to-face), tornando o acesso a esses meios de resolução de litígios por vezes inacessível do ponto de vista econômico. As longas distâncias que podem separar os litigantes inviabilizam o recurso aos meios tradicionais de resolução de controvérsias, sejam tais meios jurisdicionais ou não. 
Assim, percebe-se que o uso e desenvolvimento dos MESC é de suma importância quando se trata de acesso à justiça, considerando que os meios físicos de solução de controvérsias se tornam quase impraticáveis dentro do contexto do comércio virtual, principalmente naqueles casos que envolvem baixo valor pecuniário, em que os gastos apenas deslocamento, por exemplo, superariam a quantia envolvida na demanda.

Não obstante se saiba que o uso em larga escala dos meios eletrônicos de solução de controvérsias se dá, atualmente, em relações estabelecidas no ambiente online, é importante ressaltar que os MESC também são utilizados para resolver contendas surgidas em interações físicas. Aliás, o uso da tecnologia na conjuntura dos ADR é quase uma regra atualmente. Pode-se mencionar, por exemplo, que nos procedimentos arbitrais tornou-se comum a troca de e-mails, as conferências telefônicas e as videoconferências. Todos esses e outros recursos tecnológicos passaram a ser adotados no contexto dos ADR em razão da conveniência, agilidade e economia que conferem.

Eckschmidt, Magalhães e Muhr (2016) também indicam como fatores que impulsionaram o uso e desenvolvimento dos MESC: o crescimento do comércio eletrônico, o aumento do tempo que as pessoas gastam com deslocamento físico, principalmente em razão dos congestionamentos cada vez maiores; o aumento do custo do transporte; o aumento do volume de trabalho desenvolvido pelas pessoas no dia-a-dia; e a crescente morosidade dos meios tradicionais de resolução de conflitos (Poder Judiciário).

Dessa maneira, percebe-se que os MESC aferem conveniência e podem ser considerados eficazes e benéficos para a solução de litígios.

Vislumbra-se necessário, portanto, a divulgação e o estudo desses métodos, atribuindo a eles maior divulgação e confiança, elementos essenciais para o fomento das mencionadas formas de resolução de litígios.

\section{ARBITRAGEM ONLINE}

\subsection{Conceito e características relevantes da arbitragem}

A arbitragem é um meio de solução de controvérsias escolhido por pessoas físicas ou jurídicas, e capazes de contratar, que, fazendo uso da autonomia privada, convencionam não submeter ao Poder Judiciário eventuais litígios surgidos em dada relação jurídica, referentes a direitos patrimoniais disponíveis. ${ }^{3}$ É um método que possui características próprias, que se adequam à solução de demandas específicas e geralmente complexas, como é o caso das controvérsias que envolvem sociedades empresárias e demandas de cunho internacional.

No Brasil, o instituto é regulado pela Lei n. 9.307, de 23 de setembro de 1996, alterada pela Lei n. 13.129, de 26 de maio de 2015, comumente denominada Lei de Arbitragem.

A sentença arbitral possui força de título executivo judicial, nos termos do artigo 515, inciso

3 Art. $1^{\circ}$ As pessoas capazes de contratar poderão valer-se da arbitragem para dirimir litígios relativos a direitos patrimoniais disponíveis. (BRASIL, 1996). 
$\mathrm{VII}^{4}$, do Código de Processo Civil Brasileiro (CPC), restando, assim, juridicamente equiparada à sentença emanada do Poder Judiciário, conforme também é estabelecido na Lei de Arbitragem.

"Art. 31. A sentença arbitral produz, entre as partes e seus sucessores, os mesmos efeitos da sentença proferida pelos órgãos do Poder Judiciário e, sendo condenatória, constitui título executivo". (BRASIL, 1996).

Dentre as características que se destacam, e que geralmente levam à escolha do método, pode-se mencionar a celeridade, a especialidade do julgador, a confidencialidade e a flexibilidade.

O método é considerado célere quando é comparado ao Poder Judiciário e alguns fatores contribuem para que o procedimento arbitral transcorra com rapidez, dentre os quais pode-se indicar a especialidade do julgador, sua dedicação à solução do litígio e a ausência de recursos.

Ressalte-se que a formação da decisão dentro de um prazo razoável é de grande importância e, talvez, um dos aspectos mais perseguidos quando se fala de resolução de litígios. Nesse sentido, vê-se necessário que a resposta ao litígio se dê em tempo hábil "e capaz de realizar os objetivos da jurisdição". (CORTÊS; MAGALHÃES, 2006, p. 85).

Sobre o tema, Rodovalho ensina que:

A arbitragem, por sua vez, é célere. A própria Lei de Arbitragem fixa-lhe prazo de seis meses para terminar, ainda que não seja incomum sua prorrogação. Mas, mesmo com a prorrogação, a média das principais câmaras arbitrais é de pouco mais de um ano de duração, com realização de provas e audiências. Isso sem se falar nas chamadas arbitragens expeditas, mais céleres ainda. Sendo a arbitragem resolvida em sentença final, não cabe recurso para impugná-la, cabe apenas Pedido de Esclarecimento (assemelhado aos embargos de declaração, no CPC). Assim, uma vez proferida a sentença arbitral, pode-se tão somente tentar-lhe a anulação por vício procedimental, mas não de mérito. (RODOVALHO, 2015, p. $15)$.

Quanto à especialidade do julgador, considerando que as partes escolhem o profissional que irá resolver a demanda, este, em regra, possui conhecimentos técnicos correlatos à matéria objeto da controvérsia. Dessa maneira, essa característica permite a adequada compreensão do conflito, possibilitando que o convencimento daquele que julga se dê de maneira apropriada, gerando, a partir disso, melhores condições para que a decisão do caso seja justa.

Em relação à confidencialidade, embora ela não seja indicada como obrigatória na Lei Brasileira de Arbitragem, é, quase sempre, estabelecida nas arbitragens nacionais e internacionais, dado um costume de contratualmente empregar o sigilo aos procedimentos arbitrais. Geralmente a confidencialidade é estabelecida na convenção de arbitragem e, quando aplicável, no regulamento de arbitragem eleito pelas partes para resolução da controvérsia. Essa característica possibilita a preservação da reputação, no mercado, dos envolvidos, conferindo, por isso, vantagens econômicas 5 .

4 Art. 515. São títulos executivos judiciais, cujo cumprimento dar-se-á de acordo com os artigos previstos neste Título: [...] VII - a sentença arbitral; [...] (BRASIL, 2015).

5 Para maior aprofundamento sobre os impactos econômicos financeiros quanto ao uso da arbitragem, consultar (LEMES, 2007). 
A flexibilidade também é considerada como um benefício quanto ao uso arbitragem e que enseja a opção pelo método. Por meio dela, as partes, fazendo uso da autonomia da vontade, têm a possibilidade de, juntamente com os árbitros, determinar a forma de condução do procedimento, estabelecendo os prazos e a forma de cumprimento destes, a maneira como se dará a produção de provas, a lei aplicável que será aplicada para solução da demanda, dentre outras especificidades que permitem que cada procedimento seja moldado para a solução de cada divergência em específico. Tal característica permite que as partes exponham seus argumentos da maneira mais adequada, conferindo aos árbitros boas condições para formulação de uma boa decisão.

Todas essas características tornam a arbitragem atrativa, essencialmente quando se trata de demandas de alta complexidade que não poderiam ser discutidas e analisadas adequadamente sem o uso do método, levando em conta suas especificidades.

Neste sentido, é também relevante explanar sobre a compreensão atual sobre o que se entende por acesso à justiça ${ }^{6}$.

Hodiernamente, compreende-se que ter acesso à justiça ${ }^{7}$ não significa tão somente ter acesso a um meio de se processar uma demanda. Verifica-se ser necessário que a decisão, como resultado, seja justa, e que a forma como isso se dará tenha efetividade, incluindo-se, aqui, a necessidade de que o processo não seja moroso.

Neste sentido, Cavani ensina:

Em sendo assim, o processo, pelo menos na sua dimensão particular deve trazer um resultado. Mas não qualquer resultado. Tem de ser um que se espelhe na máxima medida do possível as exigências do direito material. Daí que se entenda que a tutela oferecida aos direitos (ou melhor: às situações jurídicas que são levadas ao processo) deve ser efetiva, adequada e tempestiva. Uma decisão produto de uma estrutura adequada que traga, no plano físico, efetividade em tempo proporcional (ou seja, sem dilações indevidas), pode ser chamada de justa. Essa justiça, refletida na tutela dos direitos, é o rasgo característico do processo do Estado Constitucional. (CAVANI, 2014, p. 121-122).

Dentro desse contexto é que os MESC ganham relevo, a partir do entendimento de que cada conflito, de acordo com suas peculiaridades, será melhor resolvido por determinado método, não restando mais o entendimento de que o Poder Judiciário é o único capaz de conferir o acesso à justiça aos cidadãos. Assim, o processo judicial passa a ser observado apenas como mais uma maneira, juntamente com tantas outras, de efetivar a mencionada garantia constitucionalmente estabelecida ${ }^{8}$.

6 Esse entendimento, como se verá, também será relevante para a observação da conveniência do uso dos métodos eletrônicos de solução de controvérsias.

7 Para melhor compreensão do tema e sobre as ondas que transformaram a compreensão sobre acesso à Justiça, consultar (CAPPELLETTI; GARTH, 1998).

8 Na Constituição da República de 1988 (CR88), o acesso à justiça é considerado fundamental e constitui um princípio, estabelecido no art. $5^{\circ}$, inciso XXXV que dispõe: "a lei não excluirá da apreciação do Poder Judiciário lesão ou ameaça a direito" (BRASIL, 1998). Sobre o assunto, Casado Filho (2014) menciona que essa garantia também está presente nas principais Convenções Internacionais de Direitos Humanos e é reconhecida como princípio da inafastabilidade da jurisdição. De acordo com a CR88, todos devem ter garantido o acesso à justiça, "para postular tutela jurisdicional preventiva ou reparatória relativa a um direito. $\mathrm{O}$ direito contempla não só direitos individuais, 
Compreendidos os aspectos relevantes quando à arbitragem e a atual abordagem sobre acesso à justiça, passa-se a observar as peculiaridades da arbitragem online.

\subsection{Peculiaridades da arbitragem online}

A arbitragem é considerada online quando parte ou todo o procedimento se desenvolve em um ambiente tecnológico relacionado ao uso da internet. Assim, "não é a origem da disputa que determina se um procedimento arbitral é online, mas sim a maneira com que é conduzido" (MUHR, 2013, p. 837-839).

Não é raro, como dito, o uso da tecnologia ligada ao ciberespaço para desenvolvimento do procedimento arbitral, sendo comum, as trocas de e-mails, as conferências telefônicas e videoconferências.

Nesse tipo de procedimento, todas, ou quase todas as características do instituto são preservadas, contudo, com alguns aspectos diferentes da arbitragem realizada totalmente em ambiente físico, sendo alguns mais relevantes.

No que tange à celeridade, esta característica se potencializa, considerando que, com o uso dos meios eletrônicos, a troca de informações se dá de forma mais rápida, permitindo, inclusive, que se economize o tempo que seria necessário para deslocamento para reuniões ou audiências. Um exemplo que demonstra o aspecto obstaculizador que advém do tempo despendido para tanto, diz respeito ao profissional escolhido para julgar a demanda. É possível imaginar casos em que aquele que possui a competência técnica necessária para atuar como árbitro reside em localidade afastada da sede da arbitragem, exigindo deste o dispêndio de diversas horas com a locomoção, além daquelas necessárias para a reunião ou audiência em si. Tal situação pode fazer com que o expert deixe de ser indicado pelas partes ou que, sendo ele convidado, não aceite o encargo, impedindo que o profissional com o conhecimento técnico adequado, e de confiança das partes, atue no procedimento.

A distância pode ser também considerada um obstáculo naquelas demandas que envolvem partes, advogados e assistentes técnicos que residem longe do local onde ocorreriam os encontros referentes ao procedimento arbitral, dificultando e encarecendo a participação desses.

Tomando a situação do expert acima indicada, pode-se extrair que a especialidade técnica do julgador pode ser beneficiada pelo uso de recursos tecnológicos que retirem ou reduzam a necessidade de deslocamento. O que se quer dizer com isso é que com a facilidade de realização dos atos procedimentais à distância, é possível que se indique profissionais residentes em qualquer localidade do mundo, desde que possuam acesso aos recursos tecnológicos necessários.

Dessa maneira, o leque de profissionais disponíveis para o encargo aumenta sobremaneira, beneficiando o procedimento arbitral.

Quanto à flexibilidade, essa se mostra um elemento importante quando se trata de um procedimento arbitral online. Por meio dela, que é originada na autonomia privada das partes,

como também os difusos e coletivos" (CASADO FILHO, 2014, p. 63). 
torna-se viável que os envolvidos convencionem a forma como a arbitragem se desenvolverá, permitindo que recursos tecnológicos como e-mail e videoconferência sejam empregados no desenrolar da arbitragem.

No que tange à confidencialidade, esta é corroborada na arbitragem online, considerando o sigilo inerente às trocas de informações pela internet, comumente estabelecido nas legislações que tratam sobre o tema. Dessa maneira, além da confidencialidade contratualmente estabelecida entre os envolvidos, em geral, as normas que regem o uso da internet preveem também o sigilo do conteúdo trocado. A título de exemplo, no Brasil, a lei n. 12.965/2014, conhecida como Marco Civil da Internet, determina a inviolabilidade das informações transmitidas online.

Art. $7^{\circ} \mathrm{O}$ acesso à internet é essencial ao exercício da cidadania, e ao usuário são assegurados os seguintes direitos: I - inviolabilidade da intimidade e da vida privada, sua proteção e indenização pelo dano material ou moral decorrente de sua violação; II - inviolabilidade e sigilo do fluxo de suas comunicações pela internet, salvo por ordem judicial, na forma da lei; III - inviolabilidade e sigilo de suas comunicações privadas armazenadas, salvo por ordem judicial; IV - não suspensão da conexão à internet, salvo por débito diretamente decorrente de sua utilização; V - manutenção da qualidade contratada da conexão à internet; VI - informações claras e completas constantes dos contratos de prestação de serviços, com detalhamento sobre o regime de proteção aos registros de conexão e aos registros de acesso a aplicações de internet, bem como sobre práticas de gerenciamento da rede que possam afetar sua qualidade; VII - não fornecimento a terceiros de seus dados pessoais, inclusive registros de conexão, e de acesso a aplicações de internet, salvo mediante consentimento livre, expresso e informado ou nas hipóteses previstas em lei; VIII - informações claras e completas sobre coleta, uso, armazenamento, tratamento e proteção de seus dados pessoais, que somente poderão ser utilizados para finalidades que: a) justifiquem sua coleta; b) não sejam vedadas pela legislação; e c) estejam especificadas nos contratos de prestação de serviços ou em termos de uso de aplicações de internet; IX consentimento expresso sobre coleta, uso, armazenamento e tratamento de dados pessoais, que deverá ocorrer de forma destacada das demais cláusulas contratuais; $X$ - exclusão definitiva dos dados pessoais que tiver fornecido a determinada aplicação de internet, a seu requerimento, ao término da relação entre as partes, ressalvadas as hipóteses de guarda obrigatória de registros previstas nesta Lei; XI - publicidade e clareza de eventuais políticas de uso dos provedores de conexão à internet e de aplicações de internet; XII - acessibilidade, consideradas as características físico-motoras, perceptivas, sensoriais, intelectuais e mentais do usuário, nos termos da lei; e XIII - aplicação das normas de proteção e defesa do consumidor nas relações de consumo realizadas na internet. (BRASIL, 2014).

Algumas vantagens também podem ser indicadas pelo uso da tecnologia online. É possível citar o conforto que as partes e os árbitros possuem em realizar os atos à distância, tornando possível, inclusive, que a troca de informação seja feita de forma assíncrona. Nessa situação, a manifestação ocorrerá no momento em que cada envolvido entender oportuno, ainda que os outros não estejam online naquele instante. Exemplo disso é o diálogo que pode se estabelecer por e-mail. 
Nessa situação, o envolvido no procedimento se comunica no horário que possui ocioso. Destarte, não há necessidade de correspondência de agenda entre os participantes do procedimento. (MUHR, 2013).

Outra conveniência atrelada à arbitragem online diz respeito à redução de gastos 9 .

Sendo possível a realização de atos à distância e no ambiente virtual, economiza-se o que seria despendido com aluguel de salas de reunião, com transporte e hospedagem e até mesmo com os honorários de profissionais (como dos árbitros, advogados e assistentes técnicos) que podem ser estabelecidos em montante reduzido dado o menor tempo que será utilizado para participação da demanda.

Não obstante tenham sido verificados tantos aspectos positivos, há que se ressaltar que existem desvantagens que envolvem o procedimento arbitral online e que devem ser objeto de cuidado quando do seu uso.

Algumas inconveniências relevantes podem ser destacadas.

Inicialmente pode-se mencionar o menor contato pessoal entre os participantes. Sabese que a oralidade é uma característica comum do método em questão, que permite a melhor exposição dos fatos. Apesar da possibilidade do uso de videoconferência, este recurso não consegue reproduzir totalmente a experiência de uma reunião presencial, além de poder contar com dificuldades que envolvem o uso de tecnologias como, por exemplo, a perda de conexão com a internet por qualquer dos participantes em meio a uma reunião online, prejudicando o seu desenvolvimento.

Outro ponto que pode se mostrar um fator de preocupação, diz respeito ao maior risco de quebra de sigilo. A possibilidade de vazamento de informações ou invasão de sistemas no ambiente online é real nesse contexto, tornando-se necessários maiores investimentos no sentido de garantir a segurança e a inviolabilidade das informações envolvidas no procedimento.

A autenticidade das informações disponíveis no ambiente online também se torna uma questão importante no que tange à arbitragem online.

Conforme ensina Muhr (2013, p. 588-594):

A segurança é outro fator fundamental nos processos de MESC por estar relacionada, não só à autenticidade da identidade das partes, mas também à integridade e confidencialidade das informações fornecidas e armazenadas. Com a finalidade de preservar esses dados, usam-se mecanismos de proteção, que incluem assinatura digital e certificação digital, para garantir que estejam presentes os atributos de autenticidade, integridade e não-repúdio. A transmissão de dados também deve utilizar o mecanismo de segurança SSL (Secure Socket Layer), além de trafegarem somente criptografados.

9 De acordo com pesquisa realizada pelo Comitê Brasileiro de Arbitragem - CBAr, o custo da arbitragem é visto como a maior desvantagem da utilização do método quando comparado a processos judiciais. Não obstante um primeiro grupo, cerca de $60 \%$ dos entrevistados, tenha informado não encontrar nenhuma desvantagem no uso da arbitragem, um "segundo grupo foi então questionado sobre qual seria a principal desvantagem e o 'custo da arbitragem' aparece com larga margem em primeiro lugar (60\%)" (ABBUD, 2012, p. 14). 
Um empecilho relevante que se observa no que tange ao uso dos ODR e que também afeta o uso da arbitragem online, diz respeito à ausência de regras específicas sobre o uso dos métodos em ambiente online, conferindo uma insegurança jurídica aos usuários ou potenciais usuários dos MESC.

Conforme ensina Amorim (2017), a United Nation on International Law - UNCITRAL que já produziu regras $\left(\right.$ soft-law $\left.w^{10}\right)$ referentes ao uso da arbitragem e ao comércio eletrônico, possui desde 2010 projeto que propõe a criação de regulamento sobre a resolução online de litígios. A entidade vislumbrou a necessidade de regulação do assunto, essencialmente pela sua importância no que se refere ao acesso à justiça sobre os conflitos relativos ao comércio eletrônico internacional. O grupo de trabalho responsável pelos estudos que concernem à elaboração do regulamento vem enfrentando diversas dificuldades no encaminhamento do tema desde o início. Dentre as dificuldades existentes, observa-se a divergência de entendimento sobre a lei aplicável ao caso e a fixação de uma jurisdição competente; as discrepâncias entre as leis internas de cada país sobre a permissão do uso dos MESC; bem como a dúvida sobre a aplicação da Convenção de Nova York sobre o Reconhecimento e a Execução de Sentenças Arbitrais Estrangeiras às decisões emanadas dos ODR. (AMORIM, 2017).

Considerando a ausência de uma regra internacional que torne mais segura e homogênia o uso dos MESC, é importante, no contexto da arbitragem, considerando a sua flexibilidade, que essas questões correlacionadas sejam bem definidas e reguladas pelas próprias partes e árbitros, evitando-se problemas no desenrolar do procedimento arbitral, inclusive no que tange à validade da convenção de arbitragem. Nesse contexto, como observado por Muhr (2013), poder-se-ia tomar como base para normatização do método as regras estabelecidas no Novo Código de Processo Civil no contexto do processo judicial eletrônico, as regras da UNCITRAL sobre comércio eletrônico e sobre arbitragem internacional, bem como a mencionada Convenção de Nova York.

Assim, não obstante, de fato, seja perceptível o benefício do estabelecimento de uma softlaw que regule os MESC para que seu uso se torne mais seguro, é possível que, até que isso ocorra, se faça o uso de todas as regras acima mencionadas, de forma a buscar soluções e direcionamento ao uso da arbitragem online, lançando mão de uma interpretação teleológica que permita encontrar respostas razoáveis e adequadas para possíveis questões controversas que surgirão no âmbito da arbitragem online, sendo importante também, como dito, a atenção dos envolvidos (árbitros, partes e câmaras) no sentido de estabelecer parâmetros, prevenindo problemas e obstáculos no desenvolvimento do procedimento.

\section{CONCLUSÃO}

A quarta Revolução Industrial, considerada ainda em curso, mudou substancialmente a forma de interação e desenvolvimento da sociedade.

O incremento tecnológico atual promove alterações paulatinas nas relações humanas,

10 Normas que não são juridicamente obrigatórias, possuindo limitação em seu valor normativo. Como exemplo, podem-se mencionar as diretrizes elaboradas pela International Bar Association (IBA). 
tendo influenciado mudanças substanciais na forma de surgimento e enfrentamento dos conflitos.

Nesse diapasão, a multiplicidade de novos litígios que surgem a partir do uso de inovações tecnológicas e da interação por estas viabilizada necessita ser tratada de acordo com suas peculiaridades, sendo os ODR importantes ferramentas para a resolução de demandas nesse contexto, considerando principalmente a comum distância física que existe entre as partes envolvidas no conflito.

Observou-se que os ODR são instrumentos que podem ser capazes de tratar tanto os novos tipos de conflitos que surgiram a partir da interação online, como também auxiliar na solução de controvérsias oriundas de relações estabelecidas no ambiente físico, conferindo diversas vantagens em ambos os contextos.

No que tange à arbitragem, como se viu, a utilização de recursos tecnológicos vem sendo paulatinamente empregada no desenvolvimento dos procedimentos, sendo, a partir disso, denominada arbitragem online, em razão do uso de ferramentas tecnológicas na totalidade dos atos ou em parte deles.

Ponderando-se as vantagens e desvantagens do uso da arbitragem online, é perceptível a conveniência de sua adoção, não obstante deva-se atentar para os possíveis problemas surgidos em razão de seu uso, como a potencialização da violação de confidencialidade e a maior dificuldade de confirmação da autenticidade das informações prestadas.

Conclui-se, assim, pela conveniência de elaboração de uma soft-law que confira maios segurança para o uso dos MESC e em especial para a arbitragem online. Enquanto essa situação não se materialize, é importante o cuidado dos envolvidos no sentido de estabelecer de forma clara e eficiente as regras aplicáveis ao caso concreto, preservando sempre a higidez, o bom andamento e a validade do procedimento.

\section{REFERÊNCIAS}

ABBUD, André de Albuquerque Cavalcanti. Arbitragem no Brasil: pesquisa CBAr-Ipsos. São Paulo, SP: Comitê Brasileiro de Arbitragem, 2012. Relatório. Disponível em: http://www.cbar. org.br/PDF/Pesquisa_CBAr-Ipsos-final.pdf. Acesso em: 2 maio 2017.

AMORIM, Fernando Sérgio Tenório de. A resolução online de litígios (ODR) de baixa intensidade: perspectivas para a ordem jurídica brasileira. Pensar: Revista de Ciências Jurídicas, Fortaleza, CE, v. 22, n. 2, p. 514-539, maio/ago. 2017.

BRASIL. [Constituição (1988)]. Constituição da República Federativa do Brasil. Brasília: Senado Federal, 1998.

BRASIL. Código de processo civil brasileiro. Brasília, DF: Senado Federal, 2015.

BRASIL. Lei no 12.965/2014, de abril de 2014. Marco Civil da Internet. Estabelece princípios, garantias, direitos e deveres para o uso da Internet no Brasil. Brasília, DF: Presidência da República, 2014. Disponível em: http://www.planalto.gov.br/ccivil_03/_ato2011-2014/2014/lei/ 112965.htm. Acesso em: 30 maio 2017. 
BRASIL. Lei no 9.307, de 23 de setembro de 1996. Dispõe sobre a arbitragem. Brasília, DF: Presidência da República, 1996. Disponível em: http://www.planalto.gov.br/ccivil_03/leis/19307. htm. Acesso em: 30 maio 2017.

CAPPELLETTI, Mauro; GARTH, Bryant. Acesso à justiça. Porto Alegre, RS: Sergio Antônio Fabris, 1998.

CASADO FILHO, Napoleão. Arbitragem comercial internacional e acesso à justiça: o novo paradigma do Third Party Funding. 2014. 2018 f. Tese (Doutorado em Direito) - Faculdade de Direito, Pontifícia Universidade Católica de São Paulo, São Paulo, 2014.

CAVANI, Renzo. "Decisão justa": mero slogan? Por uma teorização da decisão judicial para o processo civil contemporâneo. Revista de Processo, São Paulo, v. 39, n. 236, p. 119-155, 2014.

CONTREIRAS, Pedro Augusto Rodrigues. A quarta revolução industrial: um estudo de caso realizado na empresa Lix de Tecnologia. Revista Gestão, Inovação e Negócios, Anápolis, GO, v. 1, n. 1, p. 79-97, 2015.

CORTÊS, Osmar Mendes Paixão; MAGALHÃES, Ana Luiza de Carvalho M. O acesso à justiça e a efetividade da prestação jurisdicional: o inciso LXXVIII do art. $5^{\circ}$ da Constituição Federal inserido pela EC 45/2004. Revista de Processo, São Paulo, v. 31, n. 138, p. 79-91, jun. 2006.

DI FELICE, Massimo. As formas digitais do social e os novos dinamismos da sociabilidade contemporânea. In: KUNSCH, Margarida M. Krohling; KUNSCH, Waldemar Luiz (org.). Relações públicas comunitárias: a comunicação em uma perspectiva dialógica e transformadora. São Paulo: Summus Editorial, 2007.

DIMAS, Isabel Cristina Dórdio; LOURENÇO, Paulo Renato; MIGUEZ, José. (Re)Pensar os conflitos intragrupais: desempenho e níveis de desenvolvimento. Psicologia, Lisboa, PT, v. 21, n. 2, p. 183-205, 2007. Disponível em: http://www.scielo.mec.pt/scielo.php?script=sci arttext\&pid=S0874 20492007000200011. Acesso em: 10 jan. 2017.

ECKSCHMIDT, Thomas; MAGALHÃES, Mario E. S.; MUHR, Diana. Do conflito ao acordo na era digital: meios eletrônicos para solução de conflitos - MESC. 2 ed. Curitiba: Doyen, 2016.

KATSH, Ethan; RIFIKIN, Janet. Online dispute resolution: resolving conflicts in cyberspace. San Francisco: Jossey-Bass, 2001.

LEMES, Selma Maria Ferreira. Arbitragem na administração pública: fundamentos jurídicos e eficiência econômica. São Paulo: Quartier Latin, 2007.

MOORE, Christopher W. O processo de mediação: estratégias práticas para a resolução de conflitos. Tradução de Magda França Lopes. Porto Alegre, RS: Artmed, 1998.

MORAIS, Fernando Vinícius Tavares Magalhães. A exoneração da responsabilidade civil dos contratantes na Convenção das Nações Unidas sobre contratos de compra e venda internacional de mercadorias de 1980: uma análise dos requisitos do artigo 79 (1) da CISG. Revista de Arbitragem e Mediação Empresarial, Belo Horizonte, MG, ano 2, n. 2, p. 63-86, jan./jun. 
2015.

MUHR, Diana. Arbitragem online: tendências e legislação aplicável à arbitragem online no Brasil. São Paulo: CLAMARB, 2013. E-book Kindle.

NATALINO, Enrique Carlos. O petróleo e a governança energética global: dilemas contemporâneos. Revice: Revista de Ciências do Estado, Belo Horizonte, MG, v. 2, n. 2, p. $165-$ 188. ago./dez. 2017.

RODOVALHO, Thiago. Aspectos introdutórios da arbitragem. In: MANUAL de arbitragem para advogados. Brasília: Confederação das Associações Comerciais e Empresariais do Brasil, 2015. p. $10-17$.

SCHWAB, Klaws. A $4^{\text {a }}$ revolução industrial. Tradução de Daniel Moreira Miranda. São Paulo: Edipro, 2016.

Comocitar: MAGALHÃES, RodrigoAlmeida; SARAIVA, Marina de Souza .ArbitragemEletrônica. Scientia Iuris, Londrina, v. 23, n. 2, p. 26-41, jul. 2019. DOI: 10.5433/2178-8189.2019v23n2p26. ISSN: $2178-8189$.

Recebido em: 19/08/2018.

Aprovado em: 02/05/2019. 